\title{
ANTECEDENTS AND CONSEQUENCES OF CHRONIC IMPULSIVE BUYING: CAN IMPULSIVE BUYING BE UNDERSTOOD AS DYSFUNCTIONAL SELF- REGULATION?
}

\author{
Mark Fenton-O’Creevy ${ }^{\mathrm{a}}$, Sally Dibb ${ }^{\mathrm{b}}$, and Adrian Furnham ${ }^{\mathrm{c}}$
}

a. Corresponding author, Open University Business School, mark.fentonocreevy@open.ac.uk, Tel. +441908655804

b. Open University Business School \& Faculty of Business and Law, Coventry University, ac3494@ coventry.ac.uk, Tel. +44 2477654820

c. Department of Psychology, University College London \& Norwegian School of Management Oslo, a.furnham@ucl.ac.uk, Tel. +44 2076795395

This is the authors' pre-publication version of the paper. The version of record can be found at https://doi.org/10.1002/mar.21078

The authors gratefully acknowledge the collaboration of the BBC LabUK team, the BBC Watchdog production team and Martin Lewis in helping design the questionnaire and managing the online data collection for the study reported on in this paper. They also gratefully acknowledge financial support from the Friends Provident Foundation to carry out analysis of the data. They further acknowledge the helpful contribution of the editor and anonymous reviewers to improving the quality of this paper. 
ANTECEDENTS AND CONSEQUENCES OF CHRONIC IMPULSIVE BUYING: CAN IMPULSIVE BUYING BE UNDERSTOOD AS DYSFUNCTIONAL SELF-REGULATION?

\section{ABSTRACT}

Researchers reach different conclusions about the functional or dysfunctional nature of impulsive buying behavior. Whilst many note the use of impulsive buying as a form of mood regulation, there is disagreement about whether this is functional or dysfunctional and the extent to which it causes financial harm. This paper draws on data from a UK national survey sample $(\mathrm{N}=109,472)$ to contribute to these debates. Study results suggest that impulsive buying is more common for those who have most need to regulate mood and who have the least effective emotion regulation strategies. This suggests that impulsive buying may be understood as a failure of self-regulation in relation to long term goals and as a strategy for mood regulation. Contrary to some prior claims in the retail management and marketing research literature, the study shows higher levels of impulsive buying to be associated with more adverse financial outcomes (which are not confined to the most extreme manifestations of the trait). Whilst ineffective emotion regulation is associated with higher propensity to buy impulsively, the findings also suggest that effective emotion regulation may to some extent mitigate the adverse consequences of the propensity to buy impulsively. The implications for ethical management, research, and policy are considered.

Keywords: impulsive buying; emotion regulation; financial distress; social marketing, ethics 
Accounts of impulsive buying as a positive or harmless activity are common. For example, on the basis that their study participants showed no guilt or buyer's remorse, Atalay and Meloy (2011) argue that impulsive buying often acts as an effective mood regulation strategy and that this 'retail therapy' behavior has little or no downside. Researchers in consumer and retail marketing have often argued that impulsive buying either leads to positive outcomes or is harmless. They argue, for example, that: "impulse buying is not always viewed negatively by consumers, but represents a rational alternative to more time-consuming search behaviors" (Hausman, 2000); and that there are important "socio-psychological benefits of shopping and impulse purchasing" (Bayley \& Nancarrow, 1998: 113). Thompson, Locander, and Pollio (1990) propose that impulsive buying may be understood as an act of freedom in which the need for analytical evaluation is obviated because the product's 'rightness' is experienced directly.

However, other work has emphasized potentially adverse outcomes of impulsive buying behaviors. Consumer welfare research on compulsive buying, which is at the more pathological end of the impulsive buying spectrum, highlights negative consequences such as credit card debt (e.g. Joireman, Kees, \& Sprott, 2010). This raises the question of whether there is a meaningful distinction between harmless/beneficial impulsive buying and pathological compulsive buying.

This paper reports on analysis of a national (UK) survey sample $(\mathrm{N}=109,472)$ to contribute additional evidence to these debates. The reported study offers a significant empirical contribution to the debate about whether impulsive buying represents a functional or dysfunctional behavior. First, it presents evidence and arguments that impulsive buying is more common amongst people with dysfunctional emotion regulation habits and for those with personality profiles, which render them more susceptible to positive or negative reinforcement. Second, it shows impulsive buying to be dysfunctional in that it is strongly 
associated with a wide range of negative financial outcomes. Third, it suggests that effective emotion regulation, can, to some extent, mitigate the association between impulsive buying and financial harm. Further, the study suggests that impulsive buying is not only financially detrimental beyond some threshold which marks pathology. Rather the pattern is of continually increasing financial harm across the range of scores on the impulsive buying measure. In other words, significant numbers of consumers are sacrificing financial wellbeing for a short-term sense of emotional wellbeing. From these insights, the paper highlights a series of ethical concerns for firms, marketers, and researchers; and identifies policy implications for tackling the potential financial distress arising from impulsive buying.

The report on the study is in two parts. The first analysis examines hypothesized antecedents of impulsive buying. The second analysis examines the relationship between impulsive buying and financial outcomes.

In part 1, this paper reviews evidence that impulsive buying is commonly used as a strategy for mood regulation and repair. The following section considers evidence for the role of the behavioral approach and behavioral inhibition systems in relation to impulsive buying; both through direct impacts on impulsive behavior and through the generation of the negative emotions associated with anxiety. Consequently, hypotheses are developed and tested concerning the relationship between impulsive buying and the behavioral approach and inhibition systems, and the role of impulsive buying in compensating for poor emotion regulation capabilities.

Part 2 of this paper, develops and tests hypotheses concerning the relationship of impulsive buying and emotion regulation strategies with financial outcomes, and concludes by offering recommendations for research and policy.

\section{IMPULSE BUYING AND THE SELF-REGULATION OF EMOTION}


Self-regulation is the process by which individuals bring themselves into alignment with relevant goals. Most people have both long and short-term financial goals. These may include having sufficient money to pay the rent or house loan, retaining enough money to pay utilities, and saving for a holiday or retirement. Most people self-regulate their impulses to spend money on some immediately satisfying purchases to stay within a budget that allows for the achievement of longer term goals. Thus, buying behavior is the target of selfregulation activity. However, buying behavior may also be an instrument of self-regulation. As well as financial goals, individuals have hedonic goals and can be strongly motivated to maintain a positive mood or repair a negative mood. For some, buying can be a route to positive emotions, whether through positive emotions generated by 'self-gifting' (Faber \& Vohs, 2004), buying for others (Ward \& Tran, 2008) or enjoyment of the 'ability to choose' represented by the buying process itself (Rick, Pereira, \& Burson, 2014).

The role of buying behavior in generating positive emotions seems particularly important in impulsive buying. Rook and Fisher (1995) define impulsive buying as a consumer's tendency to buy spontaneously, unreflectively and immediately; regarding it as a relatively stable behavioral trait, albeit subject to situational influences. Impulsive buyers report positive emotional experiences when buying impulsively, such as feeling enthusiastic, excited and happy (Verplanken \& Herabadi, 2001). Using a field study, diary study and experiment, Atalay and Meloy (2011) showed that consumers often use unplanned indulgent purchases to repair a bad mood or fortify a good mood. In their review of impulsive buying research, Verplanken and Sato (2011) note evidence for an association between both positive and negative emotions and impulsive buying. Drawing on studies of consumption at times of natural disasters, Kemp, Kennett-Hensel, and Williams (2014) show the role of consumption behaviors in mitigating anxiety generated by loss of control in wider life domains. The implication is that impulsive buying behavior might on the one hand be understood as a 
failure of self-regulation in relation to financial goals, or on the other as a strategic, and perhaps effective, method for self-regulation of mood.

These two explanations may not be contradictory. Based on a review of self-control literature, Baumeister (2002) argues that emotional distress leads to emotion repair goals taking precedence over other self-regulatory goals (such as saving money). Hence failures of self-regulation in relation to one goal, such as sticking to a budget, may be explained by priority being given to another, such as emotion repair.

If a primary cause of poor regulation of spending behavior is the short term priority given to regulation of mood, then it might be expected a) that people with access to more effective or less costly emotion regulation practices will have less recourse to impulsive buying as an emotion regulation tool; b) that those more sensitive to the positive reinforcement provided by the experience of shopping will be more liable to engage in impulsive buying; and c) that those more vulnerable to emotional pain will be more likely to use impulsive buying for emotion repair.

While there is a paucity of studies that directly examine the role of emotion regulation processes in impulsive buying, a systematic review of impulsive buying research suggests that mood management may be an important mediating variable (Xiao \& Nicholson, 2013). Thus, an important class of explanation for impulsive buying behavior is that it is used both as a strategy for the up-regulation or maintenance of positive mood and for the downregulation of negative mood. Access to a large data set $(\mathrm{N}=109,472)$ from a UK nationwide survey that includes data on impulsive buying, personality and emotion regulation provides the rare opportunity to test this account with data from the general population.

\section{BEHAVIORAL APPROACH AND AVOIDANCE}


This section considers the influence of two fundamental personality variables on impulsive buying. It considers the evidence for the influence of behavioral approach sensitivity and the mixed evidence on the influence of behavioral inhibition sensitivity. The section concludes by proposing a resolution to the mixed evidence on behavioral inhibition and proposes a pathway from behavioral inhibition sensitivity via increased anxiety to a propensity to buy impulsively.

Reinforcement sensitivity theory (RST) is a cross-species biological theory of personality. RST characterizes individual differences in reactivity to appetitive stimuli, and self-regulation in relation to threat of punishment, in terms of two distinct neurobiological systems: the Behavioral Activation system (BAS) and the Behavioral Inhibition System (BIS) (Gray \& McNaughton, 2003). These systems are theorized to operate independently to regulate behavior in relation to threat and opportunity. The BAS is sensitive to signals of reward and non-punishment and its activation increases approach behaviors towards these stimuli. The BIS is involved in the regulation of conflicts between positive and aversive stimuli, especially when a positive stimulus or goal needs to be approached in the presence of perceived threat. BIS activation increases anxious monitoring of such conflicts. Both systems have evolved to play important adaptive roles in the regulation of behavior, but there are significant inter-individual differences in the sensitivity of the two systems.

Individual differences in BIS and BAS sensitivity have a significant genetic element (Cloninger, 1994) and there is strong evidence for their neurological underpinnings (Gray \& McNaughton, 2003). High BAS sensitivity increases the probability of impulsive rewardoriented behaviors and the experience of positive emotion in relation to perceived opportunity, whilst high BIS sensitivity increases attention to conflicting reward and punishment signals and the experience of negative emotion (fear and anxiety) in relation to 
response conflicts (Amodio, Master, Yee, \& Taylor). ${ }^{1}$ High BIS sensitivity is implicated in a range of anxiety disorders (Gray \& McNaughton, 2003).

Prior research on approach/avoidance and impulsive buying has identified BAS sensitivity as an important antecedent of both impulsive and compulsive buying behavior; individuals with higher BAS sensitivity will be more sensitive to the potential hedonic rewards offered by impulsive buying behavior and more likely to behave impulsively (see e.g. Claes et al., 2010; Dholakia, Gopinath, Bagozzi, \& Nataraajan, 2006; Verplanken \& Sato, 2011). The BAS also promotes learning from rewarding stimuli. Hence high BAS sensitivity will not only increase the probability of responding to the reward potential of impulse buying in a specific shopping situation, but will also increase likelihood of future impulsive buying through learning from the positive emotional experience.

\section{H1: Chronic reactivity to appetitive stimuli (BAS sensitivity) will be positively associated with chronic impulsive buying.}

There is conflicting evidence on BIS and impulsive buying; which is considered below, and a resolution offered.

Previous studies vary in the role they accord the BIS. Based on findings from a scenario study, Dholakia et al. (2006) argue that increased BIS sensitivity reduces the desire for rewards and enactment of temptations, since it reduces impulsivity and inhibits the expression of desire. Likewise, Claes et al. (2010) argue that compulsive buying behavior will be highest for a combination of high BAS and low BIS, although in their study of 129 female students, they do not find a significant association between BIS and compulsive buying, nor do they find any interactive effect between BIS and BAS.

\footnotetext{
${ }^{1}$ Early accounts of BIS framed it as a system concerned with promoting avoidance of threat. More recent work suggests this to be more a function of the fight-flight-freeze system with the BIS acting as a system to monitor response conflicts.
} 
By contrast, in an integrative review of impulsive buying research, Verplanken and Sato (2011) argue that a prevention-focused orientation among consumers (underpinned by the BIS) may be associated with a greater need for emotion repair in everyday life, since high BIS sensitivity is associated with high levels of anxiety. Roberts, Manolis, and Pullig (2014) find anxiety, which is underpinned by BIS, to be an important predictor of compulsive buying; especially among those with personality profiles which make them susceptible to social anxiety. Thus, rather than reducing impulse buying behavior, high BIS sensitivity, by increasing the likelihood and intensity of negative emotional experience, may increase the need for emotion repair and increase the likelihood of using impulse buying to do so.

In line with this argument, Voth et al. (2014) find that a group of patients being treated for compulsive buying have higher BIS sensitivity than a control group. Similarly, other studies have found the personality dimension of neuroticism to be associated with impulsive buying (e.g. Olsen, Tudoran, Honkanen, \& Verplanken, 2016). Neuroticism and BIS sensitivity are closely correlated. BAS and BIS sensitivity were conceived as related to neuroticism and extroversion through a 30 degree rotation of the axes in the plane defined by introversion-extraversion and emotional stability - emotionality, such that high (low) BIS relates to high neuroticism, low extraversion (low neuroticism, high extraversion) (Carver \& White, 1994)).

Both Gray and McNaughton (2003) and Carver and White (1994) suggest there may be important differences between the effects of BIS and BAS sensitivities in one shot, low stakes, lab experiments, and chronically, over extended periods, in everyday life. This arises from the important distinction between neuroticism and BIS. Whist, neuroticism is a measure of general tendency to experience anxiety, BIS measures the strength of relationship between potentially anxiety raising events and the level of anxiety they provoke. To put this another 
way, the association between BIS and anxiety is moderated by the incidence of anxiety provoking events.

This distinction may help to resolve discrepant findings on the role of BIS in impulsive buying behavior. There are key differences in the role anxiety may play in the studies cited above. Dholakia et al. (2006) find higher BIS sensitivity to be associated with lower expressed desire and less likelihood to succumb to temptation. However, their study involves a low stakes scenario study in a neutral setting, in which no conditions beyond the focal scenario are likely to arouse negative emotions amongst the student participants. Thus, the emotions in play in this experiment are most likely 'integral emotions' which relate to the task at hand. Given the time-limited nature of the study, the likelihood of a significant proportion of the participants experiencing 'incidental emotions' arising from anxiety promoting life events concurrent to the study is low. In this setting, the primary role of BIS sensitivity may be to sensitize participants to make the 'right', rather than the 'desirable' decision.

By contrast, in the Voth et al. (2014) study in which a cohort of known compulsive buyers is compared to a control sample, the evidence of compulsive buying comes from the daily impact of these tendencies on participants' lives. Here, it seems likely that compulsive buying in one context is a response to incidental emotion, namely BIS related anxiety generated in another part of the life domain. In the Claes et al. (2010) study, the sample is restricted to patients being treated for eating disorders, likely leading to a restriction of range problem with propensity to anxiety. In the present study, participants in a large and broad non-clinical sample are asked to respond to questions about their experiences in their everyday lives, increasing the likely link between BIS and experienced anxiety consequent on life events. 
The BIS promotes regulative sensitivity: sensitivity to the need to resolve conflicts between different stimuli and different goals (Gray \& McNaughton, 2003). High BIS sensitivity is associated with a high propensity to anxiety associated with the need to resolve these conflicts, and has been proposed as the primary system underlying chronic anxiety. If, as the evidence cited above suggests, impulsive buying is often used to regulate negative mood, those most likely to use impulsive buying as a form of emotion regulation are those most liable to experience negative moods. As high BIS sensitivity predicts propensity to experience negative emotion in the face of potentially anxiety promoting life events, it is hypothesized that:

H2: Chronic regulative sensitivity (BIS) will be positively associated with chronic impulsive buying.

\section{ANTECEDENT FOCUSED AND OUTCOME-FOCUSED EMOTION REGULATION}

Whilst there is ample evidence of the use of impulsive buying to regulate emotion and repair mood, there is controversy as to whether this represents functional or dysfunctional behavior. This question has two important components. This section considers the first component; whether impulsive buying is substituted for other more effective and less costly emotion regulation strategies. A later section considers the association between impulsive buying and financial harms.

Whilst impulsive buying may be used to regulate emotion and may be effective, at least short term, it is also a costly strategy; conflicting with other goals (budgeting, saving etc.) and, in more compulsive forms, leading to later negative emotions such as guilt, shame and regret. Thus, consumers with access to more effective, less costly emotion regulation strategies are likely to have less recourse to impulse buying behavior to regulate emotion. 
A substantial body of research shows intentional cognitive emotion regulation strategies to reduce experience of negative emotion, increase experience of positive emotion, and reduce physiological arousal in response to emotion stimuli. In contrast, expressive suppression strategies reduce experience of positive emotions and either leave unaffected or increase experience of negative emotions and increase physiological arousal in response to emotion stimuli (Gross, 2007). Further, suppression strategies are costly in terms of cognitive effort and physiological response (Gross \& Thompson, 2007). As Baumeister and colleagues have shown, self-regulation resources are limited (Baumeister, 2002; Baumeister, Bratslavsky, Muraven, \& Tice, 1998; Muraven \& Baumeister, 2000). Suppression is costly in self-regulation resources whilst not reducing the experience of negative emotion.

If impulsive buying acts as a form of emotion regulation, habitual use of other forms of emotion regulation that are less costly financially, cognitively and in terms of goal conflict, should reduce dependence on impulsive buying for self-regulation purposes. Thus, those who habitually use reappraisal strategies should have less need for other forms of emotion regulation, such as impulsive buying, to enhance mood or down-regulate negative emotion. In contrast, habitual use of suppression strategies will likely lead to greater need for mood enhancement or repair and, because of regulatory resource depletion (Baumeister, 2002), reduce ability to resist temptation. There is some experimental evidence for such a conclusion. Kemp and Kopp (2011) present evidence from a scenario based experimental study on undergraduate students that chronic use of intentional cognitive emotion regulation strategies (reappraisal) was associated with lower impact of negative emotions on the intention to purchase hedonic goods in a scenario task.

\section{H3. Habitual use of reappraisal strategies for emotion regulation will be associated with lower levels of impulsive buying.}




\section{H4. Habitual use of suppression strategies for emotion regulation will be associated with higher levels of impulsive buying.}

\section{METHODS}

The data for this study were collected as part of a broader UK-wide omnibus survey of attitudes to money and financial affairs conducted in collaboration with the BBC television public broadcaster. The online survey was publicized on a primetime BBC 1 consumer affairs television program, several regional radio programs, and through the $\mathrm{BBC}$ website. Participants were told that their involvement would help scientists to understand how and why people think and feel differently about money.

As an incentive, participants were offered the following benefits, following completion of the online questionnaire: (i) automated video and web feedback on key selfreported financial capability measures; (ii) their score on a financial knowledge test; and (iii) a video of a television presenter offering them tips on personal financial management.

There were 109,472 participants of which $46.7 \%$ were male. The ages of those participating ranged from 16 to 85 (a small number of participants reporting implausible ages were dropped from analysis), with a mean of 39.58 years $(\mathrm{SD}=14.35) .91 .4 \%$ were "White British”, 4\% were Asian British and 1.4\% were Black British. 7\% lacked school qualifications, $26 \%$ had been educated to GCSE/O Levels/ $10^{\text {th }}$ Grade or equivalent, while $19 \%$ had A Levels (12 ${ }^{\text {th }}$ Grade), $36 \%$ were graduates and $12 \%$ had a postgraduate degree. Annual gross income was distributed as follows: $7.3 \%$ earned less than $£ 10,000,22.7 \%$ between $£ 10,000-19,999,17.4 \% £ 20,000-£ 29,999,14.8 \%$ between $£ 30,000-£ 39,999,12.1 \%$ between $£ 40,000-£ 49,999,15.3 \%$ over $£ 50,000$ and $6.6 \%$ either did not know or preferred not to say. 
The full dataset is deposited with the UK Data Service and available to researchers (Fenton-O’Creevy \& Furnham, 2017).

\section{ANALYSIS 1}

Analysis 1 examines hypothesized antecedents of impulsive buying. This is followed by a second analysis that considers and tests the relationship of impulsive buying and emotion regulation with financial outcomes.

\section{Measures}

Dependent variable, Impulsive Buying, Rook and Fisher's (1995) Buying Impulsiveness Scale. The original 9 item scale was shortened due to space constraints in the survey, choosing the five items loading most strongly on the single factor in the original study. Items "I often buy things without thinking", "I often buy things spontaneously", "“I see it, I buy it' describes me", "'Just do it' describes the way I buy things", "“Buy now, think about it later' describes me" (Alpha =0.90). Impulsive Buying as measured in the survey exhibited a left censored normal distribution, which is a common outcome from shortening scales. A Tobit regression (Long, 1997) was used which adjusts parameter estimates and standard errors to account for the censored distribution.

Control measures. Age (in years), gender, wealth (respondents were asked to estimate total wealth by making separate estimates for value of house less any mortgage, other physical assets, and savings and investments), total income, self-reported social class, highest educational qualification, and financial knowledge (a ten-item test of financial literacy, scored as the number of correct answers).

Emotion Regulation. The Emotion Regulation Questionnaire (Gross, 2002) was used to measure habitual use of an intentional cognitive strategy for emotion regulation (Reappraisal) and an outcome focused strategy (Expressive Suppression). 
BIS/BAS: Carver and White (1994) developed the Behavioral Inhibition Scale (BIS) and Behavioral Approach Scale (BAS) to assess individual differences in the sensitivity of these systems. BIS measures the sensitivity of the individual to anxiety provoking stimuli; and BAS the sensitivity to reward. Whilst Carver and White designed these scales to be unidimensional, their study and later studies identified three sub-components of BAS: Drive (strong pursuit of goals), Fun-Seeking (craving for and impulsive approach to novel rewards) and Reward-Responsiveness (positive reaction to rewards or their anticipation). Thus, the present study uses BIS and the three BAS subscales.

\section{Results}

Table 1 reports the results of the Tobit regression on Impulsive Buying. All coefficients are standardized. The largest effect among the control variables is gender, with women showing greater mean impulsive buying than men. Greater income is associated with higher impulsive spending, perhaps reflecting greater discretionary spending power. By contrast, two measures of wealth (house value and investments) have an inverse association with Impulsive Buying, perhaps representing greater difficulty in budgeting and saving among impulsive buyers. Education, financial knowledge and self-classified social class all have an inverse association with impulsive buying. Age shows an inverse association with impulsive buying behavior in model 1. However, this association declines in model 2 when the BIS/BAS variables are entered and becomes non-significant when emotion regulation is added in model three. This suggests that the higher incidence of impulsive buying among the young may be explained by the, well documented, association of improved emotion regulation with age (Urry \& Gross, 2010) and the decline of BIS BAS reactivity with age (Jorm et al., 1998). 
H1 is partially supported, with higher BAS Drive and BAS Fun Seeking associated with higher Impulsive Buying (both of these BAS facets are associated with impulsiveness (Franken, Muris, \& Rassin, 2005)). However, there is a small but significant negative association between BAS Reward Responsiveness and Impulsive Buying (this appears to be a co-linearity effect as entered without the other BIS and BAS variables it shows a significant positive association). $\mathrm{H} 2$ is supported with a positive coefficient for BIS, showing that greater BIS is associated with greater Impulsive Buying.

$\mathrm{H} 3$ and $\mathrm{H} 4$ were concerned with the relationship between emotion regulation and Impulsive Buying. Both hypotheses are supported with Reappraisal showing a significant inverse relationship with Impulsive Buying, and Expressive Suppression showing a positive association with Impulsive Buying.

Two additional questions enabled motivations for impulsive shopping to be further examined. Participants were asked to respond true (coded 1) or false (coded 0$)$ to these questions: "Does shopping make you feel good in a way that nothing else does?", and "Do you often spend money when you are feeling depressed worthless or worried?”. A Tobit regression of Impulsive Buying on these two variables and their interaction shows significant main effects for both, and a significant (reinforcing) interactive effect on Impulsive Buying.

TABLE 2 ABOUT HERE

The coefficients can be interpreted as the mean difference (as the proportion of a standard deviation) in Impulsive Buying between the group of participants responding true and false to each question. This analysis further evidences the role of responsiveness to the positive hedonic impact of purchasing and the compensatory role of purchasing in mood repair as important factors in impulsive buying behavior.

Next, we consider the relationship between impulsive buying and financial outcomes. 


\section{ANALYSIS 2}

\section{Impulsive buying behavior and adverse financial outcomes}

If impulsive buying can be understood as a form of self-regulation, this does not mean it is necessarily dysfunctional. Some have argued (e.g. Bayley \& Nancarrow; Hausman) that buying on impulse represents a rational alternative to more time-consuming search behaviors. Many studies, either tacitly or explicitly, treat impulsive buying as either positive or harmless, in that they make recommendations for retailers on how impulsive buying behavior may be increased (e.g. Spears, 2006). Others have argued that impulsive buying, at least in its more extreme forms, is dysfunctional. For example, significant adverse outcomes have been shown to include debt, depression and marital discord (Joireman et al., 2010). In these cases, it seems likely that research participants are prioritizing short term emotional benefits over financial wellbeing. However, studies concerned with harmful impulsive buying have focused on the more pathological end of the spectrum, compulsive buying. Since research that argues impulsive buying to be either beneficial or harmless often focuses on developing prescriptions for retail managers, this question deserves rather closer scrutiny:

\section{H5: Impulsive buying will be associated with greater difficulty in making ends meet and greater risk of adverse financial life events.}

The previous analysis showed the impact of BIS, BAS, and emotion regulation on impulsive buying. If hypothesis 5 is correct, then there will be an indirect effect of these variables on financial wellbeing. However, it is also important to consider the possibility of a direct effect ${ }^{2}$. First, there is evidence that more effective emotion regulation is associated with more effective financial decision-making (e.g. see: Fenton-O'Creevy et al., 2012 ; Fenton-O'Creevy, Soane, Nicholson, \& Willman, 2011). Hence:

\footnotetext{
${ }^{2}$ The authors are grateful to an anonymous reviewer for encouraging us to consider this.
} 
H6: Chronic emotion regulation will be associated with financial outcomes such that greater use of reappraisal will be associated with less difficulty in making ends meet and lower risk of adverse financial life events, and greater use of suppression will be associated with greater difficulty in making ends meet and greater risk of adverse financial events.

Second, whilst the earlier analysis suggests that mood maintenance and repair motivates impulsive buying, this may only account for a proportion of impulsive buying behavior. Emotion regulation and BIS/BAS explain only a proportion of variance in impulsive buying behavior. This raises the question as to whether habitual impulsive buying which is motivated by emotion repair has differential effects on financial outcomes to habitual impulsive buying, which arises from other causes. For example, it may be that highly anxious individuals with ineffective emotion regulation practices are less able to modulate their impulsive buying in relation to their financial situation and goals. This would imply that the effects of impulsive buying on financial outcomes are moderated by habitual patterns of emotion regulation and by BIS/BAS profile. Hence:

H7: The relationship between impulsive buying and financial outcomes is moderated such that the relationship is stronger for $(\mathrm{H7a})$ lower reappraisal, $(\mathrm{H7b})$ higher suppression, (H7c) higher BIS, and (H7d) higher BAS.

\section{Measures and data analysis}

Making ends meet. The UK Financial Services authority (FSA) carried out a baseline survey of financial capabilities (Atkinson, McKay, Kempson, \& Collard, 2006), from which factor analysis identified five core financial capabilities. Four items, from the FSA 'Making Ends Meet' factor, were used in this study. All items were among the highest loading on this factor and focused on outcomes rather than attitudes. Items: "Which of these statements best 
describes how well you are keeping up with your bills and credit commitments at the moment?" (1 - real problems behind with many things to 5 - fine, no difficulties); "I am very organized when it comes to managing my money day to day" (1 - disagree strongly to 5 agree strongly); "In the last 12 months, how often have you run out of money before the end of the week/month, or needed to use your credit card or overdraft to get by?" ( 1 - always to 5 - never); "In the last five years have you found yourself in financial difficulties? By that we mean three months or more behind with payments on your regular commitments" ( 1 - no, 5 yes $)($ Alpha $=0.75)$.

Adverse financial events index. Study participants were asked if they had experienced any of the following adverse financial events in the last five years: bankruptcy, repossession of house; repossession of car, repossession of other goods bought on credit, missing one or more payments on a loan or mortgage, denial of credit, unexpected overdraft ( 1 - yes, 0 no). The adequacy of the index as a scale was assessed using Mokken analysis, a probabilistic version of Guttman scaling that assumes items follow a hierarchy in which those highest imply the truth of the items below. In Mokken scaling, if an item is true, items lower in the hierarchy are assumed to be 'probably' true. The H score is a measure of the extent of violations of the hierarchical structure with a higher $\mathrm{H}$ score indicating fewer violations (van Schuur, 2003). The $\mathrm{H}$ score was 0.69 , (item $\mathrm{H}$-score range between 0.46 and 0.69 , reliability rho $=0.67)$; indicating a good fit to the Mokken assumptions.

Making Ends Meet showed a right censored non-normal distribution. Analysis was carried out using Tobit regression to account for the distribution. The adverse financial events index had a distribution typical of count data, with a large proportion of zero scores. Negative binomial regression, which is suitable for an independent variable constructed from count data (Long, 1997), was used in the analysis involving the adverse financial life events index as the DV. 
In each case models were also tested that include main effects and interactions with buying impulsiveness for emotion regulation and BIS/BAS variables. Since a curvilinear relationship between the moderated IV and the DV can give rise to detection of spurious interaction effects, the analysis controls for this by including the square of impulsive buying in the interaction models.

The effects reported in this adverse financial events analysis are likely to be most influenced by the more common/less extreme events. However, the size of the available sample also makes it practical to study rare events. A logistic regression analysis was carried out separately for the extreme event of bankruptcy. Since bankruptcy is a rare event $(1.3 \%$, 1412 cases in the sample of 109,372 answering the question), it is necessary to use a rare events adjusted version of logistic regression (King \& Zeng, 2001). The analysis approach used was Firth Logistic regression. The analysis controlled for age, gender, income, wealth, social class, education and financial knowledge.

Finally, to explore whether adverse effects of buying impulsiveness concentrate at the extreme end of the scale, as would be expected if adverse effects are primarily associated with compulsive buying, the marginal means of key financial variables are examined for different levels of the Impulsive Buying score.

\section{Results}

Table 3 reports the results of the Tobit regression on Making Ends Meet and Table 4, the results of the Negative Binomial Regression on the Adverse Financial Life Events Index.

\section{TABLE 3 ABOUT HERE}

Considering the control variables: ability to make ends meet increases with age, education, financial knowledge, social class, income and wealth and is lower for women than 
men. However, the parameter for education becomes non-significant once Impulsive Buying is entered, suggesting the effect of education may be mediated by Impulsive Buying.

Examining models 1 and 2 in table 3, as hypothesized (H5), Impulsive Buying shows a significant inverse association with Making Ends Meet, explaining 6\% of the unique variance. Entering the squared term for Impulsive Buying gives a significant parameter and adds $7 \%$ unique variance, suggesting a curvilinear (quadratic) relationship.

\section{TABLE 4 ABOUT HERE}

Turning to models 1 and 2 in table 4 , all control variables show significant associations with adverse financial events, with the exception of value of physical assets (non-housing). Experience of adverse financial events in the last five years decreases with age, being female, income, wealth (housing and investments), education, financial knowledge and social class.

As hypothesized (H5), Impulsive Buying is significantly associated with the Adverse Financial Events Index. Examining the exponential of the coefficient suggests a one standard deviation increase in Buying Impulsivity is associated with a $22 \%$ increase in the Adverse Financial Events Index. Adding the squared term for Impulsive Buying results in a significant coefficient but little change to variance explained, suggesting a (modestly) curvilinear relationship.

Turning to the logistic regression analysis, Impulsive Buying has a significant coefficient $(.20, \mathrm{p}<0.0001)$. With control variables held at mean values, an increase in Impulsive Buying of 1 standard deviation is associated with a relative increase in the likelihood of bankruptcy of $22 \%$. The coefficients for BIS, BAS and emotion regulation variables are non-significant. The relative change in likelihood of bankruptcy across the observed range of values for Impulsive Buying amounts to $218 \%$. 
Turning to hypotheses 6 and 7, the relevant results are in model 3 and 4 in table 3 and model 3 and 4 in table 4. As hypothesized (H6) the main effect of Reappraisal is associated with greater ability to make ends meet and the main effect of Suppression with lower ability to make ends meet. However, neither of these main effects achieve significance when regressed on the Adverse Financial Events Index.

Examining the interaction effects for Making Ends Meet (table 3, model 4), the only significant interaction is of Reappraisal with Impulsive Buying, such that higher Reappraisal is both associated with higher scores on Making Ends Meet and reduces the negative effect of Impulsive Buying on Making Ends Meet, consistent with H7a.

There are significant negative main effects on Making Ends Meet of BIS, BAS-FS and Suppression. There are significant positive main effects on Making Ends Meet of BAS-D and Reappraisal. The main effect of BAS-RR is not significant.

Examining the interaction effects for the Adverse Financial events index, the only significant interaction is BAS-RR with Impulsive Buying, such that higher BAS-RR is associated with a higher score on the Adverse Financial Events Index but a lower (positive) association between Impulsive Buying and the Adverse Financial Events Index. This is inconsistent with $\mathrm{H} 7$.

There are main effects such that higher BAS-RR and BAS-FS increase the risk of adverse financial events and higher BAS-D decreases the risk of adverse financial events. The parameter for BIS is non-significant. In summary, H7a is supported (for Making Ends Meet) but not H7b through H7d.

Finally, to explore whether financial harm is entirely or mostly associated with only the most extreme Impulsive Buying Scores, the marginal means of Making Ends Meet and the Adverse Financial Events Index are charted across groups defined by each level of the Impulsive Buying score. Because the sample is large, the smallest group includes 735 
respondents, making such partitioning reasonable. Since the scales of these measures do not have a clearly intuitive interpretation, the marginal incidence of one of the events in the Index, unexpected overdraft in the last five years, is also charted.

FIGURES $1,2 \& 3$ ABOUT HERE

Across the whole range of the Impulsive Buying scale, ability to make ends meet declines (figure 1). Likelihood of adverse financial events increases noticeably from a score of around 10 (the median) on Impulsive Buying upwards. With one exception, incidence of unexpected overdraft rises across the scale, from an incidence of around $15 \%$ in 5 years for the lowest scoring Impulsive Buying group, to around $40 \%$ for the highest scoring group.

Typical estimates of the incidence of compulsive buying in the population range from $6 \%$ to $7 \%$ (Claes et al., 2010; Voth et al., 2014). If financial harm is only or mostly associated with the compulsive buying end of the spectrum, one would expect financial harm to show primarily in the small proportion of the population scoring above 20. Instead, there is increasing incidence of financial difficulty across the top scoring $50 \%$ of the population. The greatest harms are associated with the most extreme Impulsive Buying scores, and the moderately curvilinear nature of the relationships means financial harms accelerate to some extent with rises in Impulsive Buying scores. However, increases in Impulsive Buying scores are associated with greater risk of financial harm across the range of each of the measures.

\section{DISCUSSION}

The findings support the view of impulsive buying as having an important mood regulation function. The positive association between Impulsive Buying and both BAS Drive and BAS Fun-Seeking suggest a relationship between impulsive buying and behavioral approach system sensitivity (reward reactivity). At the same time, the positive association between BIS and Impulsive Buying suggests there is also a link between impulsive buying 
and sensitivity to the negative emotion which arises from goal conflicts. The implication is that consumers engage in impulsive shopping both to down regulate negative mood and upregulate positive mood. Although there is a small negative association between BAS RewardResponsiveness and Impulsive Buying, this may be a co-linearity artefact. The results in relation to age and impulsive buying also suggest that the greater incidence of impulsive buying among the young may be explained by greater BIS BAS reactivity and poorer emotion regulation among the young ${ }^{3}$.

Impulsive Buying is positively associated with habitual use of an expressive suppression emotion regulation strategy and inversely associated with habitual use of a reappraisal emotion regulation strategy. Thus, the results are consistent with impulsive buying being used as a compensatory mechanism for poor internal emotion regulation; what Kemp and Kopp (2011) have labeled 'emotion regulation consumption'.

As noted in the introduction, use of impulsive buying as a form of emotion regulation need not be dysfunctional, it achieves hedonic goals. However, contrary to accounts that treat impulsive buying as unproblematic, or as only a concern for a small proportion of the population with pathological impulsive buying levels, this study finds evidence of significant and sizeable relationships between chronic buying impulsivity and multiple measures of adverse financial outcomes. People with higher levels of chronic buying impulsivity are more likely to have problems making ends meet, more likely to experience adverse financial events, and have a higher probability of experiencing bankruptcy. Increased financial harm is not solely associated with the most extreme end of the impulsive buying spectrum. Taken together, the findings offer support for the view that much impulsive buying behavior amounts to a dysfunctional approach to emotion regulation.

\footnotetext{
${ }^{3}$ A separate analysis also suggests that anxiety about finances peaks in the early twenties and then declines with age. Details available from the first author.
} 
Whilst, BIS, BAS and emotion regulation have indirect effects on financial outcomes, there is also evidence suggesting direct effects (or possibly effects mediated via unmeasured variables). Consistent with prior research on financial decision-making (Fenton-O'Creevy et al., 2012; Fenton-O'Creevy et al., 2011), effective emotion regulation (higher reappraisal and lower suppression) is associated with less difficulty in making ends meet, although not with lower susceptibility to adverse financial events. Reappraisal also moderates the effect of Impulsive Buying such that with greater habitual use of reappraisal emotion regulation strategies, Impulsive Buying has less detrimental effect on Making Ends Meet. This finding offers some evidence that more effective emotion regulation not only reduces propensity to buy impulsively but can mitigate the adverse financial effects of impulsive buying.

There are also significant main effects of BIS and BAS variables, suggesting that the behavioral approach and avoidance systems may have important effects on financial behavior beyond their impact on impulsive buying. As has been found in the health and gambling literatures, different facets of BAS have differential associations with behavior. Higher BAS Fun Seeking is associated with both lower capability to make ends meet and greater risk of adverse financial events. This facet of BAS is associated with dysfunctional impulsivity (Franken et al., 2005) and thus may be associated with dysfunctional impulsive financial behaviors beyond impulsive buying.

The association of higher BAS Drive with lower difficulty in making ends meet and lower risk of adverse financial events, suggests that the stronger goal focus and action orientation with which it is associated may promote more careful financial management alongside its association with more impulsive buying behavior. The results for BAS Reward Responsiveness, are difficult to interpret and we note that prior research has highlighted this facet of BAS as problematic due to its correlation with BIS (Quilty \& Oakman, 2004). 
Finally, the association of higher BIS with difficulty in making ends meet suggests that high anxiety may promote dysfunctional coping beyond impulsive buying. For example, it may be that anxiety prone individuals self-regulate emotion by avoiding triggers for anxiety such as opening bills or bank statements.

In summary, this study offers evidence to support a view of impulsive buying as a form of emotion regulation behavior that is dysfunctional to the extent that it is financially costly and associated with difficulties in regulating emotions through less costly means. The study offers evidence that the effective regulation of emotions may not only reduce impulsive buying but may also mitigate some of the harms of impulsive buying. The interactive effect of reappraisal also suggests that impulsive buying may be most harmful where used as a substitute for (rather than complement to) other more functional forms of emotion regulation.

This paper proposes a resolution to inconsistent research evidence on the relationship between BIS and impulsive buying. The results offer some support for the suggestion that BIS in the presence of anxiety provoking life events will show a positive association with impulsive buying in contrast to experiments which, absent the likelihood of strong anxiety provoking life events, show an inverse association. This proposition could be further tested by experiments on impulsive buying which expose treatment group participants to an anxiety provoking situation and examine the extent to which this moderates the BIS - impulsive buying relationship.

Important ethical implications arise from these findings. Given the relationship between impulsive buying and adverse financial outcomes, there is evidence that the net effect of retailers' efforts to encourage impulsive buying is to significantly increase financial distress in the population. These potential costs of impulsive buying behavior suggest that policy intervention is needed. In this sense, there are striking similarities between the costs of impulsive buying behavior and other threats to society's well-being; such as from the obesity 
epidemic (Pettigrew \& Pescud, 2012), binge drinking (Gordon, Moodie, Eadie, \& Hastings, 2010), and smoking (Hassan, Walsh, Shiu, Hastings, \& Harris, 2007). The evidence from this study should not be taken to suggest that the harms outweigh the benefits for all impulsive buying. However, the fact that retailers often use sophisticated merchandising and other forms of consumer engagement to preferentially target those vulnerable to impulsive buying behaviors who may consequently suffer adverse financial outcomes, is a matter of concern.

Some scholars question the effectiveness of downstream initiatives in tackling lifestyle or health issues associated with excess, such as binge drinking and obesity (Maziak \& Ward, 2009). Although initiatives such as mass media campaigns have been shown to increase awareness and instigate attitude change (e.g. Carroll, Craypo, \& Samuels, 2000), the longer-term impact on behavior change is less certain (Aldao, Nolen-Hoeksema, \& Schweizer, 2010). Thus intervention programs for tackling impulsive buying should include both up- and downstream initiatives (Hoek \& Jones, 2011). In extreme cases in which impulsive buying has become out of control and is causing negative financial or psychological outcomes, there are parallels with other forms of impulsive behavior, such as over-eating and binge drinking. Emotion regulation plays a role in all of these problem behaviors (Fox, Hong, \& Sinha, 2008). For example, (Raine, 2010: 21) describes an approach aimed at improving nutrition which '...includes traditional downstream strategies such as counseling to improve knowledge and skills; midstream strategies such as using the media to change social norms; and upstream strategies such as creating supportive environments through public policy including regulatory measures.'

The findings of this study provide insights into factors which could guide the targeting and design of content of the downstream element of interventions. Firstly, the findings identify some of the characteristics of impulsive buyers, information that helps to 
define the profile of individuals to be targeted with downstream interventions. Secondly, the link between emotion regulation and impulsive buying suggests that these downstream interventions might productively focus on helping individuals to manage their emotions. This approach is a departure from previous approaches which have tended to focus on educational programs for improving financial literacy and, which in at least some accounts, have limited success in changing dysfunctional financial behavior (Mandell, 2008; Willis, 2008). With increasing moves to encourage financial education in schools and colleges around the world (Grifoni \& Messy, 2012), these findings add to other evidence (e.g. Holden, Kock, \& Mohan, 2010) supporting the inclusion of learning on emotions and money in financial education programs. Such educational programs may be more effective if they focus on improving understanding of the role of emotions and their regulation in buying behavior and the impact of marketing approaches on emotions.

Upstream interventions could focus on policy changes that limit the use of marketing techniques designed to encourage impulsive buying, such as certain point-of-sale promotions. Pressure could also be applied on those in control of regulating advertising. Where the industry self regulates, such as in the UK, pressure from government could be used to extend current interpretations of what constitutes consumer harm.

The findings also raise ethical questions for researchers who promote the exploitation of shoppers who are high on impulsive buying traits. De Cremer, van Dick, Tenbrunsel, Pillutla, and Murnighan ( 2011) take a behavioral approach to business ethics and emphasize the role of 'ethical fading' a process in which managers fail to see the ethical components of a decision not through a lack of ethical education but through psychological processes which 'fade' moral aspects of a decision. As Tenbrunsel and Messick (2004) note, the language and decision-frames which academics construct through research, and teach in courses, can 
contribute to this process of ethical fading in its use of language and frames that deemphasize the human cost of business decisions.

The American Marketing Association ethical guidelines (2015) enshrine an important principle in this regard, to "Acknowledge the social obligations to stakeholders that come with increased marketing and economic power" and "[r]ecognize our special commitment to vulnerable market segments". This ethical position implies a responsibility to consider the social implications of targeting consumers to increase impulsive buying.

While the sample used is large and there is significant variation in the variables examined, the study does have some important limitations. First, the sample is self-selected, raising the prospect that it differs from the general UK population in some key regards. Since participation depends on a survey announced on television and conducted via the internet, the poorest groups in the population are significantly under-sampled. Second, since the data are cross-sectional, no firm attributions can be made about causality and the results are open to explanation via alternative causal paths to those proposed. 


\section{REFERENCES}

Aldao, A., Nolen-Hoeksema, S., \& Schweizer, S. (2010). Emotion-regulation strategies across psychopathology: A meta-analytic review. Clinical Psychology Review, 30(2), 217-237.

Amodio, D. M., Master, S. L., Yee, C. M., \& Taylor, S. E. (2008). Neurocognitive components of the behavioral inhibition and activation systems: Implications for theories of self-regulation. Psychophysiology, 45(1), 11-19.

Atalay, A. S., \& Meloy, M. G. (2011). Retail therapy: A strategic effort to improve mood. Psychology \& Marketing, 28(6), 638-659. doi:10.1002/mar.20404

Atkinson, A., McKay, S., Kempson, E., \& Collard, S. (2006). Levels of financial capability in the UK. Results of a baseline survey. London: Financial Services Authority.

Baumeister, R. F. (2002). Yielding to Temptation: Self-Control Failure, Impulsive Purchasing, and Consumer Behavior. Journal of Consumer Research Inc., 28, 670 676. doi:0093-5301/2002/2804-0011

Baumeister, R. F., Bratslavsky, E., Muraven, M., \& Tice, D. M. (1998). Ego depletion: is the active self a limited resource? Journal of Personality and Social Psychology, 74(5), $1252-1265$.

Bayley, G., \& Nancarrow, C. (1998). Impulse purchasing: a qualitative exploration of the phenomenon. Qualitative Market Research: An International Journal, 1(2), 99 -114.

Carroll, A., Craypo, L., \& Samuels, S. (2000). Evaluating nutrition and physical activity social marketing campaigns: A review of the literature for use in community campaigns: A report to the Center for Advanced Studies of Nutrition and Social Marketing. Davis, CA: University of California. 
Carver, C. S., \& White, T. L. (1994). Behavioral inhibition, behavioral activation, and affective responses to impending reward and punishment: The BIS/BAS Scales. Journal of Personality and Social Psychology, 67(2), 319.

Claes, L., Bijttebier, P., Eynde, F. V. D., Mitchell, J. E., Faber, R., Zwaan, M. d., \& Mueller, A. (2010). Emotional reactivity and self-regulation in relation to compulsive buying. Personality and Individual Differences, 49(5), 526-530. doi:http://dx.doi.org/10.1016/j.paid.2010.05.020

Cloninger, C. R. (1994). The genetic structure of personality and learning: a phylogenetic model. Clinical genetics, 46(1), 124-137.

De Cremer, D., van Dick, R., Tenbrunsel, A., Pillutla, M., \& Murnighan, J. K. (2011). Understanding Ethical Behavior and Decision Making in Management: A Behavioural Business Ethics Approach. . British Journal of Management, 22 S1-S4.

Dholakia, U. M., Gopinath, M., Bagozzi, R. P., \& Nataraajan, R. (2006). The role of regulatory focus in the experience and self-control of desire for temptations. Journal of Consumer Psychology, 16(2), 163-175.

Faber, R. J., \& Vohs, K. D. (2004). To buy or not to buy?: Self-control and self-regulatory failure in purchase behavior. In R. F. Baumeister \& K. D. Vohs (Eds.), Handbook of self-regulation (pp. 509-524). New York: The Guildford Press.

Fenton-O'Creevy, M., Furnham, A. (2017). BBC Big Money Test, 2011. [data collection]. UK Data Service. SN: 8132, http://doi.org/10.5255/UKDA-SN-8132-1

Fenton-O'Creevy, M., Lins, J., Vohra, S., Richards, D., Davies, G., \& Schaaff, K. (2012). Emotion regulation and trader expertise: heart rate variability on the trading floor. Journal of Neuroscience, Psychology and Economics, 5(4), 227-237. 
Fenton-O'Creevy, M., Soane, E., Nicholson, N., \& Willman, P. (2011). Thinking, feeling and deciding: The influence of emotions on the decision making and performance of traders. Journal of Organizational Behavior 32(8), 1044-1061.

Fox, H., Hong, K., \& Sinha, R. (2008). Difficulties in emotion regulation and impulse control in recently abstinent alcoholics compared with social drinkers. Addictive Behaviors, 33(2), 388-394.

Franken, I. H., Muris, P., \& Rassin, E. (2005). Psychometric properties of the Dutch BIS/BAS scales. Journal of Psychopathology and Behavioral Assessment, 27(1), 2530.

Gordon, R., Moodie, C., Eadie, D., \& Hastings, G. B. (2010). Critical social marketing - The impact of alcohol marketing on youth drinking: Qualitative findings. International Journal of Nonprofit and Voluntary Sector Marketing, 15:, 265-275.

Gray, J. A., \& McNaughton, N. (2003). The neuropsychology of anxiety: An enquiry into the function of the septo-hippocampal system: Oxford University Press.

Grifoni, A., \& Messy, F.A. (2012). Current status of national strategies for financial education: A comparative analysis and relevant practices. OECD Working Papers on Finance, Insurance and Private Pensions (16), 1.

Gross, J. (2002). Emotion regulation: affective, cognitive, and social consequences. Psychophysiology, 39, 281.

Gross, J. J. (2007). Handbook of emotion regulation. New York, NY: Guilford Press.

Gross, J. J., \& Thompson, R. A. (2007). Emotion regulation: Conceptual foundations. In J. J. Gross (Ed.), Handbook of emotion regulation. New York, NY: Guilford Press.

Hassan, L. M., Walsh, G., Shiu, E. M. K., Hastings, G., \& Harris, F. (2007). Modeling persuasion in social advertising: A study of responsible thinking in antismoking 
promotion in eight eastern EU (European Union) member states. Journal of Advertising, 36(2), 15-31.

Hausman, A. (2000). A multi-method investigation of consumer motivations in impulse buying behavior. Journal of Consumer Marketing, Vol. 17(5), 403 - 419.

Hoek, J., \& Jones, S. C. (2011). Regulation, public health and social marketing: a behaviour change trinity. Journal of Social Marketing, 1(1), 32-44.

Holden, K., Kock, S., \& Mohan, R. (2010). Theories of human behavior and emotions: What they imply about the financial behavior of vulnerable populations. University of Wisconsin Center for Financial Security, CFS Issue Brief, 4.

Joireman, J., Kees, J., \& Sprott, D. (2010). Concern with Immediate Consequences Magnifies the Impact of Compulsive Buying Tendencies on College Students' Credit Card Debt. The Journal of Consumer Affairs, 43(1), 155 - 178.

Jorm, A. F., Christensen, H., Henderson, A. S., Jacomb, P. A., Korten, A. E., \& Rodgers, B. (1998). Using the BIS/BAS scales to measure behavioural inhibition and behavioural activation: Factor structure, validity and norms in a large community sample. Personality and Individual Differences, 26(1), 49-58.

Kemp, E., Kennett-Hensel, P. A., \& Williams, K. H. (2014). The Calm before the Storm: Examining Emotion Regulation Consumption in the Face of an Impending Disaster. Psychology \& Marketing, 31(11), 933-945. doi:10.1002/mar.20744

Kemp, E., \& Kopp, S. W. (2011). Emotion regulation consumption: When feeling better is the aim. Journal of Consumer Behavior, 10(1), 1-7.

King, G., \& Zeng, L. (2001). Logistic regression in rare events data. Political analysis, 9(2), 137-163.

Long, J. S. (1997). Regression models for categorical and limited dependent variables (Vol. 7): Sage Publications, Inc. 
Mandell, L. (2008). Financial literacy of high school students. In Xiao, J.J., Handbook of consumer finance research, 163-183. Heidelberg: Springer Link

Maziak, W., \& Ward, K. D. (2009). From health as a rational choice to health as an affordable choice. American journal of public health, 99(12), 2134-39.

Muraven, M., \& Baumeister, R. F. (2000). Self-regulation and depletion of limited resources: Does self-control resemble a muscle. Psychological Bulletin, 126(2), 247-259.

Olsen, S. O., Tudoran, A. A., Honkanen, P., \& Verplanken, B. (2016). Differences and Similarities between Impulse Buying and Variety Seeking: A Personality-based Perspective. Psychology \& Marketing, 33(1), 36-47. doi:10.1002/mar.20853

Pettigrew, S., \& Pescud, M. (2012). Improving parents' child-feeding practices: a social marketing challenge. Journal of Social Marketing, 2(1), 8-22.

Quilty, L. C., \& Oakman, J. M. (2004). The assessment of behavioural activation-the relationship between impulsivity and behavioural activation. Personality and Individual Differences, 37(2), 429-442.

Raine, K. D. (2010). Addressing poor nutrition to promote heart health: moving upstream. The Canadian Journal of Cardiology, 26(Suppl C), 21C.

Rick, S., Pereira, B., \& Burson, K. A. (2014). The benefits of retail therapy: making purchase decisions reduces residual sadness. Journal of Consumer Psychology, 24(3), 373-380.

Roberts, J. A., Manolis, C., \& Pullig, C. (2014). Contingent self-esteem, self-presentational concerns, and compulsive buying. Psychology \& Marketing, 31(2), 147-160.

Rook, D. W., \& Fisher, R. J. (1995). Normative influences on impulsive buying behavior. Journal of Consumer Research, 305-313.

Spears, N. (2006). Just moseying around and happening upon it versus a master plan: Minimizing regret in impulse versus planned sales promotion purchases. Psychology \& Marketing, 23(1), 57-73. 
Tenbrunsel, A. E., \& Messick, D. M. (2004). Ethical fading: The role of self-deception in unethical behavior. Social Justice Research, 17(2), 223-236.

Thompson, C. J., Locander, W. B., \& Pollio, H. R. (1990). The lived meaning of free choice: an existential-phenomenological description of everyday consumer experiences of contemporary married women. Journal of Consumer Research, 346-361.

Urry, H. L., \& Gross, J. J. (2010). Emotion Regulation in Older Age. Current Directions in Psychological Science, 19(6), 352-357. doi:10.1177/0963721410388395

van Schuur, W. H. (2003). Mokken Scale Analysis: Between the Guttman Scale and Parametric Item Response Theory. Political Analysis, 11(2), 139-163. doi:10.1093/pan/mpg002

Verplanken, B., \& Herabadi, A. (2001). Individual Differences in impulse buying tendency: Feeling and no thinking. European Journal of Personality, Vol. 15, S71 - S83.

Verplanken, B., \& Sato, A. (2011). The Psychology of impulse buying: An integrative selfregulation approach. Journal of Consumer Policy, 1-14.

Voth, E. M., Claes, L., Georgiadou, E., Selle, J., Trotzke, P., Brand, M., de Zwaan, M., Müller, A. (2014). Reactive and regulative temperament in patients with compulsive buying and non-clinical controls measured by self-report and performance-based tasks. Comprehensive Psychiatry, 55(7), 1505-1512. doi:http://dx.doi.org/10.1016/j.comppsych.2014.05.011

Ward, C. B., \& Tran, T. (2008). Consumer Gifting Behaviors: One for You, One for Me? Services Marketing Quarterly, 29(2), 1-17.

Willis, L. (2008). Evidence and ideology in assessing the effectiveness of financial literacy education. San Diego Law Review, 46, 415. 
Xiao, S. H., \& Nicholson, M. (2013). A multidisciplinary cognitive behavioural framework of impulse buying: A systematic review of the literature. International Journal of Management Reviews, 15(3), 333-356. doi:10.1111/j.1468-2370.2012.00345.x 
TABLE 1. TOBIT REGRESSION ON IMPULSIVE BUYING

\begin{tabular}{|c|c|c|c|c|c|c|}
\hline & Model 1 & & Model 2 & & Model 3 & \\
\hline & $\boldsymbol{\beta}$ & $\mathbf{z}$ & $\boldsymbol{\beta}$ & $\mathbf{z}$ & $\boldsymbol{\beta}$ & $\mathbf{z}$ \\
\hline Age & -0.10 & $-22.45^{* * *}$ & -0.02 & $-4.05^{* *}$ & -0.01 & -2.25 \\
\hline Female & 0.15 & $41.38^{* * *}$ & 0.14 & $41.43^{* * *}$ & 0.17 & $45.90^{* * *}$ \\
\hline Wealth: house value & -0.03 & $-6.87^{* * * *}$ & -0.03 & $-7.73^{* * *}$ & -0.03 & $-7.63^{* * *}$ \\
\hline Wealth: investments & -0.11 & $-25.28^{* * *}$ & -0.10 & $-22.97^{* * *}$ & -0.10 & $-23.67^{* * *}$ \\
\hline $\begin{array}{l}\text { Wealth: physical } \\
\text { assets }\end{array}$ & 0.05 & $12.89^{* * * *}$ & 0.02 & $6.64^{* * * *}$ & 0.03 & $6.78^{* * * *}$ \\
\hline Income & 0.06 & $15.75^{* * *}$ & 0.06 & $15.45^{* * *}$ & 0.06 & $16.13^{* * *}$ \\
\hline Education & -0.11 & $-26.34^{* * *}$ & -0.11 & $-28.97^{* * *}$ & -0.10 & $-27.40^{* * *}$ \\
\hline Financial knowledge & -0.09 & $-23.70^{* * * *}$ & -0.07 & $-19.95^{* * *}$ & -0.07 & $-20.26^{* * *}$ \\
\hline Social class & -0.01 & $-3.60^{*}$ & -0.03 & $-8.72^{* * *}$ & -0.03 & $-7.86^{* * *}$ \\
\hline BIS & & & 0.13 & $36.37^{* * *}$ & 0.11 & $29.98^{* * *}$ \\
\hline $\begin{array}{l}\text { BAS Reward } \\
\text { Responsiveness }\end{array}$ & & & -0.06 & $-14.41^{* * * *}$ & -0.04 & $-8.48^{* * *}$ \\
\hline BAS Drive & & & 0.14 & $34.68^{* * *}$ & 0.14 & $35.14^{* * *}$ \\
\hline BAS Fun Seeking & & & 0.36 & $89.09^{* * *}$ & 0.37 & $91.52^{* * *}$ \\
\hline Suppression & & & & & 0.05 & $15.66^{* * *}$ \\
\hline Reappraisal & & & & & -0.10 & $-28.97^{* * * *}$ \\
\hline Log Likelihood & -148392.07 & & -140752.90 & & -140276.62 & \\
\hline Log Likelihood ratio & $6638.95^{* * *}$ & & $15278.34^{* * * *}$ & & $952.55^{* * * *}$ & \\
\hline Wald & 6808.38 & & 23783.71 & & 24920.65 & \\
\hline $\mathbf{R}^{2}$ & .06 & & .19 & & .21 & \\
\hline$\Delta \mathbf{R}^{2}$ & .06 & & .13 & & .02 & \\
\hline
\end{tabular}


ANTECEDENTS AND CONSEQUENCES OF CHRONIC IMPULSIVE BUYING

TABLE 2. TOBIT REGRESSION OF IMPULSIVE BUYING ON EMOTION QUESTIONS

\begin{tabular}{lcc}
\hline & $\boldsymbol{\beta}$ & $\mathbf{z}$ \\
\hline Does shopping make you feel good in & $0.70 * * *$ & 44.82 \\
a way that nothing else does? & & \\
Do you often spend money when you & $0.80 * * *$ & 86.10 \\
are feeling depressed worthless or & & \\
worried? & & \\
Interaction & $0.08 * * *$ & 3.67 \\
$\mathrm{R}^{2}=.22$, Log likelihood: $-140121.67 * * *$ & d.f.: 5 & \\
\hline
\end{tabular}


TABLE 3. TOBIT REGRESSION ON MAKING ENDS MEET

\begin{tabular}{|c|c|c|c|c|c|c|c|c|}
\hline \multirow[t]{2}{*}{ Variable } & \multicolumn{2}{|c|}{ Model 1} & \multicolumn{2}{|c|}{ Model 2} & \multicolumn{2}{|c|}{ Model 3} & \multicolumn{2}{|c|}{ Model 4} \\
\hline & $\boldsymbol{\beta}$ & $\bar{Z}$ & $\boldsymbol{\beta}$ & $\bar{Z}$ & $\boldsymbol{\beta}$ & $\bar{z}$ & $\boldsymbol{\beta}$ & $\bar{Z}$ \\
\hline Age & 0.12 & $27.95^{* * *}$ & .09 & $21.98^{* * *}$ & 0.09 & $21.58^{* * *}$ & 0.10 & $23.01^{* * *}$ \\
\hline Female & -0.07 & $-18.05^{* * *}$ & -.03 & $-7.55^{* * *}$ & -0.03 & $-7.94^{* * *}$ & -0.02 & $-4.42^{* *}$ \\
\hline Income & 0.09 & $21.64^{* * *}$ & .11 & $26.97^{* * *}$ & 0.11 & $26.63^{* * *}$ & 0.10 & $24.49^{* * *}$ \\
\hline Wealth: house & 0.07 & $13.86^{* * *}$ & .06 & $12.51^{* * *}$ & 0.06 & $12.67^{* * *}$ & 0.05 & $11.62^{* * * *}$ \\
\hline Wealth: investments & 0.43 & $91.28^{* * *}$ & .40 & $87.80^{* * *}$ & 0.40 & $88.00^{* * *}$ & 0.40 & $87.84^{* * *}$ \\
\hline Wealth: physical assets & 0.01 & $2.66^{\dagger}$ & .03 & $6.48^{* * *}$ & 0.03 & $6.54^{* * *}$ & 0.02 & $3.93^{* *}$ \\
\hline Social class & 0.06 & $14.34^{* * *}$ & .05 & $13.54^{* * *}$ & 0.05 & $13.32^{* * *}$ & 0.05 & $12.00^{* * *}$ \\
\hline Education & 0.03 & $8.56^{* * *}$ & .00 & 1.10 & 0.00 & 0.83 & 0.00 & 0.24 \\
\hline Financial Knowledge & 0.11 & $28.86^{* * *}$ & .08 & $23.17^{* * *}$ & 0.08 & $23.15^{* * *}$ & 0.08 & $23.51^{* * *}$ \\
\hline Impulsive Buying (IB) & & & -.31 & $-90.08^{* * *}$ & -0.28 & $-69.07^{* * *}$ & -0.27 & $-63.57^{* * *}$ \\
\hline $\mathrm{IB}^{2}$ & & & & & -0.04 & $-14.73^{* * *}$ & -0.04 & $-13.33^{* * *}$ \\
\hline BIS & & & & & & & -0.04 & $-11.47^{* * *}$ \\
\hline BAS-RR & & & & & & & 0.01 & 1.20 \\
\hline BAS-D & & & & & & & 0.13 & $31.01^{* * *}$ \\
\hline BAS-FS & & & & & & & -0.11 & $-24.51^{* * *}$ \\
\hline Suppression & & & & & & & -0.02 & $-5.27^{* * *}$ \\
\hline Reappraisal & & & & & & & 0.02 & $5.36^{* * *}$ \\
\hline BIS $x$ IB & & & & & & & -0.01 & -1.49 \\
\hline BAS-RR x IB & & & & & & & 0.00 & -0.22 \\
\hline BAS-D x IB & & & & & & & 0.01 & 1.45 \\
\hline BAS-FS x IB & & & & & & & -0.01 & -1.84 \\
\hline Suppression x IB & & & & & & & 0.00 & 0.48 \\
\hline Reappraisal x IB & & & & & & & 0.02 & $4.76^{* *}$ \\
\hline Log likelihood (df) & \multicolumn{2}{|c|}{$-135076.29(11)$} & \multicolumn{2}{|c|}{$-131141.36(12)$} & \multicolumn{2}{|c|}{$-131033.28(13)$} & \multicolumn{2}{|c|}{$-130280.29(25)$} \\
\hline Wald (df) & \multicolumn{2}{|c|}{$28623.56(9)^{* * * *}$} & \multicolumn{2}{|c|}{$38013.50(10)^{* * * *}$} & \multicolumn{2}{|c|}{$38465.88(11)$} & \multicolumn{2}{|c|}{$40233.96(23)^{* * * *}$} \\
\hline$\Delta$ Wald (df) & \multicolumn{2}{|c|}{$28623.56(9)^{* * *}$} & \multicolumn{2}{|c|}{$9389.94(1)^{* * * *}$} & \multicolumn{2}{|c|}{$452.38(1)^{\text {*** }}$} & \multicolumn{2}{|c|}{$1768.08(12)^{* * * *}$} \\
\hline $\mathbf{R}^{2}$ & \multicolumn{2}{|c|}{.207} & \multicolumn{2}{|c|}{.265} & \multicolumn{2}{|c|}{.336} & \multicolumn{2}{|c|}{.347} \\
\hline$\Delta \mathbf{R}^{2}$ & \multicolumn{2}{|c|}{.207} & \multicolumn{2}{|c|}{.058} & \multicolumn{2}{|c|}{.071} & \multicolumn{2}{|c|}{.011} \\
\hline
\end{tabular}

$* * * \mathrm{p}<.000001,{ }^{* *} \mathrm{p}<.0001,{ }^{*} \mathrm{p}<.001, \dagger \mathrm{p}<.01 ; \mathrm{R}^{2}$ is a pseudo $\mathrm{R}^{2}$, calculated as the squared correlation between predicted and

observed values of Making Ends Meet. All variables standardized. 
TABLE 4: NEGATIVE BINOMIAL REGRESSION ON ADVERSE FINANCIAL EVENTS INDEX

\begin{tabular}{|c|c|c|c|c|c|c|c|c|c|c|c|c|}
\hline \multirow[b]{2}{*}{ Parameter } & \multicolumn{3}{|c|}{ Model 1} & \multicolumn{3}{|c|}{ Model 2} & \multicolumn{3}{|c|}{ Model 3} & \multicolumn{3}{|c|}{ Model 4} \\
\hline & B & $\begin{array}{l}\text { Wald Chi- } \\
\text { Square }\end{array}$ & $\operatorname{Exp}(B)$ & B & $\begin{array}{l}\text { Wald Chi- } \\
\text { Square }\end{array}$ & $\operatorname{Exp}(B)$ & B & $\begin{array}{l}\text { Wald Chi- } \\
\text { Square }\end{array}$ & $\operatorname{Exp}(B)$ & B & $\begin{array}{l}\text { Wald Chi- } \\
\text { Square }\end{array}$ & $\operatorname{Exp}(B)$ \\
\hline (Intercept) & -1.02 & $18722.92^{* * *}$ & .36 & -1.03 & $19273.01^{\text {*** }}$ & 0.36 & - & $14702.10^{* * * *}$ & .34 & -1.07 & $14709.64^{* * * *}$ & 0.34 \\
\hline Age & -.08 & $108.11^{* * * *}$ & .93 & -0.05 & $53.78^{* * *}$ & 0.95 & $\begin{array}{l}1.06 \\
-.05\end{array}$ & $51.84^{* * * *}$ & .95 & -0.04 & $32.53^{* * *}$ & 0.96 \\
\hline Female & -.03 & $26.19^{* * *}$ & .97 & -0.05 & $75.50^{* * *}$ & 0.95 & -.05 & $74.82^{* * * *}$ & .95 & -0.05 & $59.89^{* * *}$ & 0.95 \\
\hline Income & -.06 & $66.88^{* * *}$ & .95 & -0.07 & $100.56^{\text {**** }}$ & 0.93 & -.07 & $96.88^{* * * *}$ & .94 & -0.06 & $81.61^{* * * *}$ & 0.94 \\
\hline Wealth: house & -.31 & $822.60^{* * * *}$ & .73 & -0.30 & $779.42^{* * * *}$ & 0.74 & -.30 & $780.90^{* * * *}$ & .74 & -0.30 & $760.75^{\text {*** }}$ & 0.74 \\
\hline Wealth: investments & -.67 & $3405.70^{* * *}$ & .51 & -0.64 & $3116.92^{* * * *}$ & 0.53 & -.64 & $3124.34^{* * *}$ & .53 & -0.64 & $3060.32^{* * *}$ & 0.53 \\
\hline Wealth: physical assets & -.01 & .69 & .99 & -0.02 & 3.62 & 0.98 & -.02 & 3.70 & .98 & -0.02 & 3.41 & 0.98 \\
\hline Social class & -.09 & $163.00^{* * *}$ & .92 & -0.08 & $150.20^{* * * *}$ & 0.92 & -.08 & $146.80^{* * *}$ & .92 & -0.08 & $145.69^{* * *}$ & 0.92 \\
\hline Education & -.05 & $69.43^{* * *}$ & .95 & -0.03 & $23.49^{* * *}$ & 0.97 & -.03 & $22.34^{* *}$ & .97 & -0.03 & $22.98^{* *}$ & 0.97 \\
\hline Financial Knowledge & -.04 & $46.53^{* * *}$ & .96 & -0.03 & $17.63^{* *}$ & 0.98 & -.03 & $17.38^{* *}$ & .98 & -0.02 & $13.87^{*}$ & 0.98 \\
\hline Impulsive Buying (IB) & & & & 0.20 & $1352.38^{* * *}$ & 1.22 & .17 & $606.92^{* * *}$ & 1.19 & 0.15 & $422.11^{* * *}$ & 1.16 \\
\hline IB $^{2}$ & & & & & & & .03 & $46.05^{* * *}$ & 1.03 & 0.03 & $39.17^{* * *}$ & 1.03 \\
\hline BIS & & & & & & & & & & 0.01 & 4.78 & 1.01 \\
\hline BAS-RR & & & & & & & & & & 0.05 & $48.74^{* * * *}$ & 1.05 \\
\hline BAS-D & & & & & & & & & & -0.05 & $56.22^{* * * *}$ & 0.95 \\
\hline BAS-FS & & & & & & & & & & 0.08 & $116.88^{* * *}$ & 1.08 \\
\hline Suppression & & & & & & & & & & 0.01 & 4.53 & 1.01 \\
\hline Reappraisal & & & & & & & & & & 0.00 & 0.21 & 1.00 \\
\hline BIS x IB & & & & & & & & & & 0.00 & 0.07 & 1.00 \\
\hline BAS-RR x IB & & & & & & & & & & -0.02 & $11.50^{*}$ & 0.98 \\
\hline BAS-D x IB & & & & & & & & & & 0.01 & 2.68 & 1.01 \\
\hline BAS-FS x IB & & & & & & & & & & 0.00 & 0.04 & 1.00 \\
\hline Suppression x IB & & & & & & & & & & 0.01 & 1.07 & 1.01 \\
\hline Reappraisal x IB & & & & & & & & & & 0.00 & 0.34 & 1.00 \\
\hline Likelihood ratio $\chi^{2}(\mathrm{df})$ & 15289 & $59(9)^{* * *}$ & & 16648 & $31(10)^{* * * *}$ & & 1669 & $85(11)^{* * *}$ & & 16960 & $2(23)^{* * *}$ & \\
\hline$\Delta$ LR Chi sq (df) & 15289 & $59(9)^{* * * *}$ & & 1359.1 & $(1)^{* * * *}$ & & 46.04 & 1) **** $^{*}$ & & 265.9 & 12) $)^{* * *}$ & \\
\hline $\mathbf{R}^{2}$ & .150 & & & .166 & & & .166 & & & .170 & & \\
\hline$\Delta \mathbf{R}^{2}$ & .150 & & & .016 & & & .000 & & & .004 & & \\
\hline
\end{tabular}

$* * * \mathrm{p}<.000001, * * \mathrm{p}<.0001, * \mathrm{p}<.001 ; \mathrm{R}^{2}$ is a pseudo $\mathrm{R}^{2}$, calculated as the squared correlation between predicted and observed values

of Adverse Financial Events Index $(\mathrm{N}=109,372)$. 
FIGURE1: ESTIMATED MARGINAL MEANS OF MAKING ENDS MEET

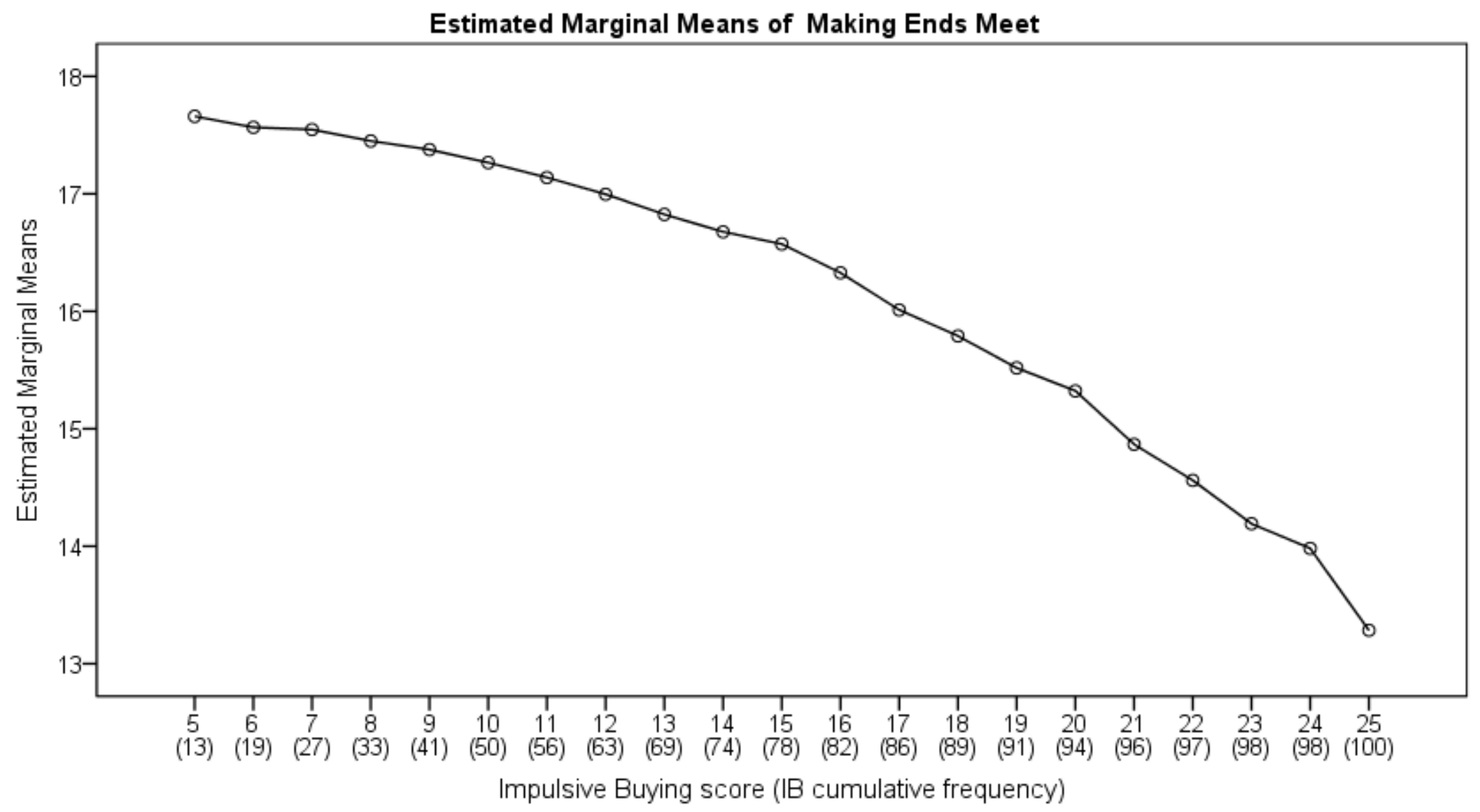

Covariates appearing in the model are evaluated at their means 
FIGURE 2: ESTIMATED MARGINAL MEANS OF ADVERSE FINANCIAL EVENTS INDEX

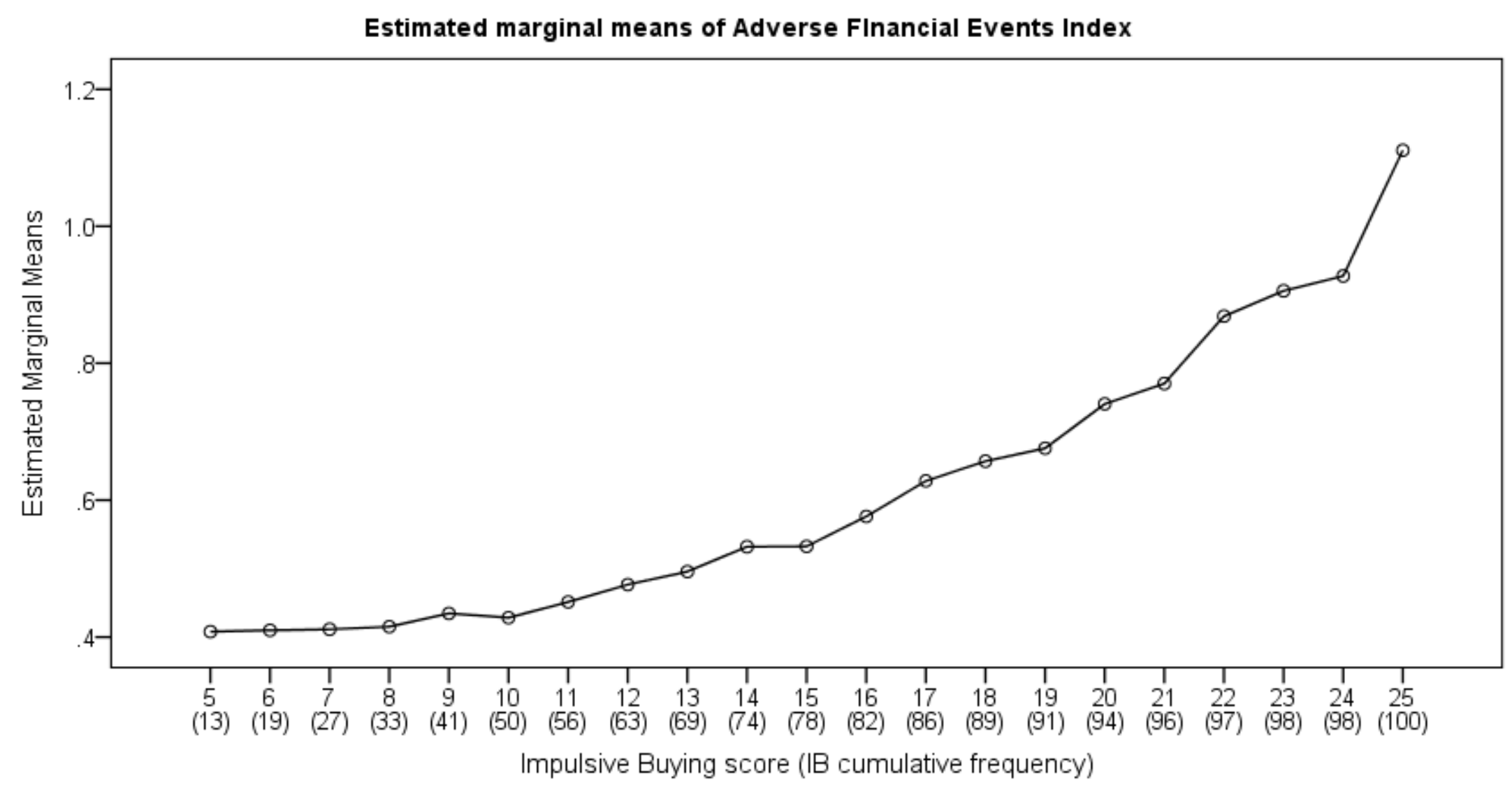

Covariates appearing in the model are evaluated at their mean values 
FIGURE 3: ESTIMATED MARGINAL PROPORTIONS OF "UNEXPECTED OVERDRAFT IN THE LAST FIVE YEARS".

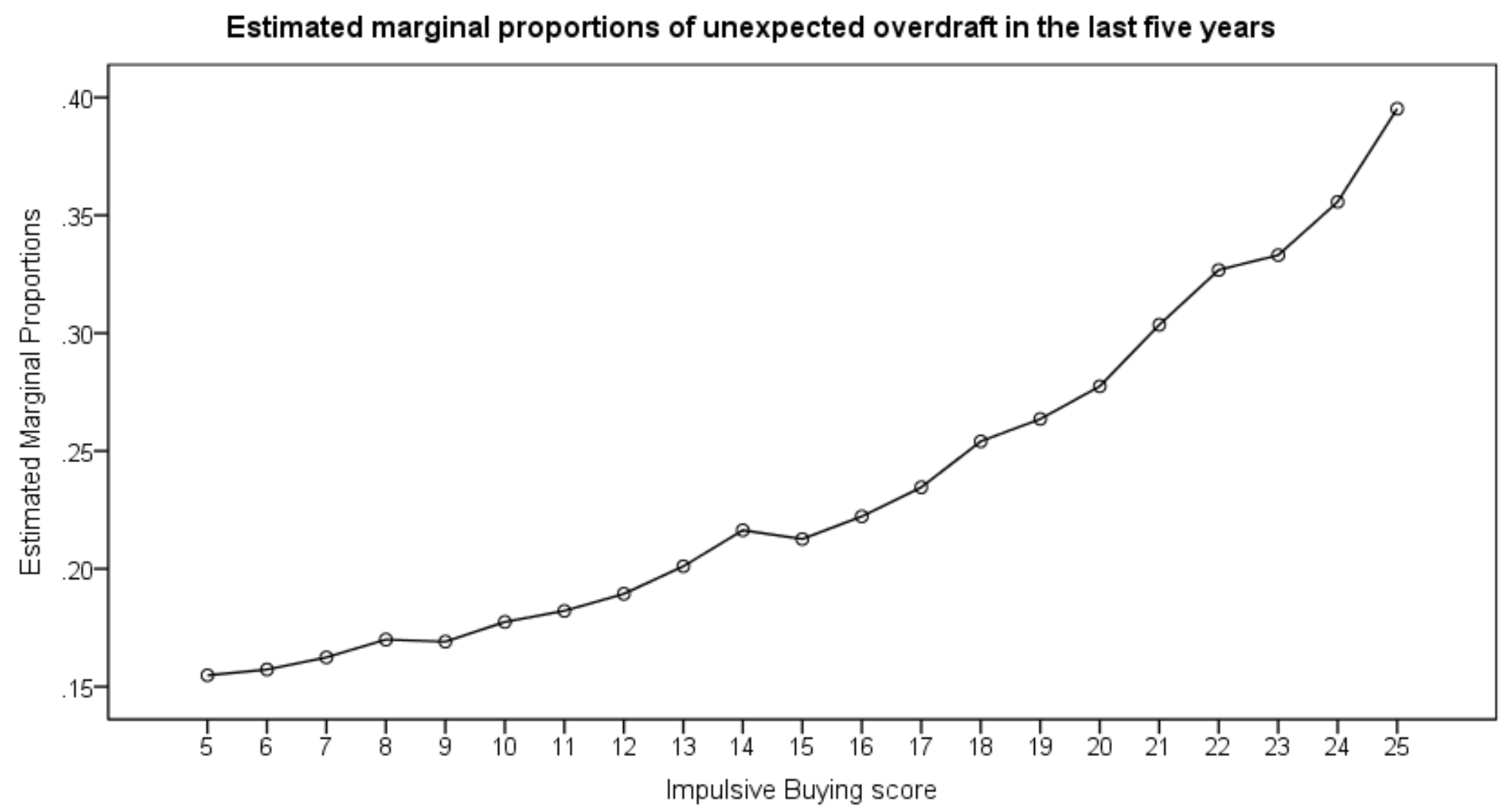

Covariates appearing in the model are evaluated at their means 